http://jmscr.igmpublication.org/home/ ISSN (e)-2347-176x ISSN (p) 2455-0450

crossref DOI: https://dx.doi.org/10.18535/jmscr/v7i8.163

Journal Of Medical Science And Clinical Research

\title{
Introduction of OSCE (Objective Structured Clinical Examination) in Neonatology for Undergraduate Students
}

\author{
Authors \\ Manab Narayan Baruah ${ }^{1}$, Pankaj Pradeep Panyang ${ }^{2}$, Ananta Kumar Nath ${ }^{2}$, \\ Dipangkar Hazarika ${ }^{2}$, Pranabjit Biswanath ${ }^{3}$ \\ ${ }^{1}$ Associate Professor, ${ }^{2}$ Assistant Professor, ${ }^{3}$ Professor \\ ${ }^{1,2,3}$ Department of Pediatrics, Jorhat Medical College, Jorhat, Assam, India, PIN-785001 \\ *Corresponding Author \\ Manab Narayan Baruah \\ Department of Pediatrics, Jorhat Medical College, Assam, India
}

\begin{abstract}
Background: OSCE is a structured assessment of predetermined competencies including psychomotor, communication and data interpretation skill us. Despite challenges in its implementation, OSCE is a feasible approach for the assessment of clinical competence across varied geographical context in different specialties and disciplines. The introduction of OSCE in a resource limited setting like Jorhat Medical College is a small yet bold step on the road to competency based medical education.

Aim: To introduce OSCE as a formative assessment tool in Final Prof MBBS.

Specific Objectives: To introduce OSCE in assessment of knowledge, skills and attitude regarding neonatal thermoregulation among $8^{\text {th }}$ semester undergraduate students.

Methodology: 85 students of the $8^{\text {th }}$ semester MBBS batch participated in the OSCE project. There were a total of eight stations comprising 2 Question stations, 4 Procedure stations, 1Observed station (on communication skills) and 1 Rest station. Peer reviewed and pre validated checklist was used for marking the procedure and observed stations. Feedback on structured questionnaire was taken from students and faculty.
\end{abstract}

Results: The majority of students (88.2\%) were satisfied with the OSCE experience. $84.7 \%$ of the students felt that OSCE was unbiased in terms of gender and ethnicity. $64.7 \%$ of students felt that OSCE minimized chances of failing while $71.8 \%$ felt that it helped to highlight areas of weakness.

Conclusion: OSCE is a step towards attainment of competency based education. It needs to be introduced in to the undergraduate curriculum to enrich existing assessment methods. The implementation of OSCE program needs meticulous planning, manpower, resources and faculty training.

Keywords: OSCE, Competency Based Medical Education, Formative Assessment, UG Curriculum, Neonatology.

\section{Introduction}

The MCI vision document 2015 highlights the need for a competency based curriculum so that the Indian Medical Graduate has the requisite knowledge, skills and attitude to handle patients effectively in real life situations. ${ }^{[1]}$ Traditional clinical assessment tools are often not competency based, and are blamed for testing only factual knowledge instead of clinical skills. They suffer 
from inherent student, patient and examiner variability leading to subjectivity in marking. So OSCE (Objective Structured Clinical Examination) was evolved to overcome the shortcomings of traditional tools. In OSCE, a structured assessment of a set of predetermined competencies including psychomotor, communication and data interpretation skills is done using a circuit of stations. With appropriate attention to design, OSCE as an assessment tool is reliable and valid. ${ }^{[2]}$ It provides a unique blending of teaching, learning and assessment methodologies. Compared to traditional tools, students seem to enjoy the challenge of demonstration of clinical skills in the OSCE setting. [3]

OSCE has been used for both formative and summative assessment of medical graduates across the globe. The use of OSCE in formative assessment creates great opportunities for learning as students can gain insight into the making of clinical competencies as well as get feedback on individual strengths and weaknesses. ${ }^{[4]}$ However, the need for standardization and structuring of an OSCE involves meticulous planning as well as resources. ${ }^{[5]}$ Despite challenges in its implementation, OSCE is a feasible approach for the assessment of clinical competence across varied geographical context in different specialties and disciplines. ${ }^{[6]}$

The OSCE format had never been used among medical colleges of north eastern India and Jorhat Medical College was no exception. The introduction of OSCE in a resource limited setting like Jorhat Medical College is a small yet bold step on the road to competency based education.

The Indian Medical Graduate needs to be proficient in the management of basic neonatal problems like identification, prevention and management of hypothermia. Neonatology involves a combination of knowledge, skills and attitude which till now was not adequately addressed by traditional learning and assessment methods. Therefore there was a felt need for a standardized, more effective and objective way to assess the student's clinical performance in the field of neonatology. So, neonatal thermoregulation was chosen as the topic for the OSCE project. The successful implementation of the project will help to create awareness and acceptance of OSCE as an assessment tool among clinical departments of the institute.

The MCI vision document 2015 highlights the need for a competency based curriculum so that the Indian Medical Graduate has the requisite knowledge, skills and attitude to handle patients effectively in real life situations. ${ }^{[1]}$ Traditional clinical assessment tools are often not competency based, and are blamed for testing only factual knowledge instead of clinical skills. They suffer from inherent student, patient and examiner variability leading to subjectivity in marking. So OSCE (Objective Structured Clinical Examination) was evolved to overcome the shortcomings of traditional tools. In OSCE, a structured assessment of a set of predetermined competencies including psychomotor, communication and data interpretation skills is done using a circuit of stations. With appropriate attention to design, OSCE as an assessment tool is reliable and valid. ${ }^{[2]}$ It provides a unique blending of teaching, learning and assessment methodologies. Compared to traditional tools, students seem to enjoy the challenge of demonstration of clinical skills in the OSCE setting. [3]

OSCE has been used for both formative and summative assessment of medical graduates across the globe. The use of OSCE in formative assessment creates great opportunities for learning as students can gain insight into the making of clinical competencies as well as get feedback on individual strengths and weaknesses. ${ }^{[4]}$ However, the need for standardization and structuring of an OSCE involves meticulous planning as well as resources. $^{[5]}$ Despite challenges in its implementation, OSCE is a feasible approach for the assessment of clinical competence across varied geographical context in different specialties and disciplines. $^{[6]}$

The OSCE format had never been used among medical colleges of north eastern India and Jorhat Medical College was no exception. The introduction 
of OSCE in a resource limited setting like Jorhat Medical College is a small yet bold step on the road to competency based education.

The Indian Medical Graduate needs to be proficient in the management of basic neonatal problems like identification, prevention and management of hypothermia. Neonatology involves a combination of knowledge, skills and attitude which till now was not adequately addressed by traditional learning and assessment methods. Therefore there was a felt need for a standardized, more effective and objective way to assess the student's clinical performance in the field of neonatology. So, neonatal thermoregulation was chosen as the topic for the OSCE project. The successful implementation of the project will help to create awareness and acceptance of OSCE as an assessment tool among clinical departments of the institute.

\section{Aim \& Objectives}

Aim

To introduce OSCE as a formative assessment tool in Final Prof MBBS.

\section{Specific Objectives}

To introduce OSCE in assessment of knowledge, skills and attitude regarding neonatal thermoregulation among $8^{\text {th }}$ semester undergraduate students.

In the OSCE setting, the $8^{\text {th }}$ semester student should be able to:

- Define and grade the severity of hypothermia.

- Indicate the steps of management of hypothermia.

- Demonstrate Kangaroo Mother Care for prevention of hypothermia on mannequin.

- Demonstrate the human touch method for assessment of temperature on mannequin.

- Demonstrate the steps of measuring axillary temperature using clinical thermometer on mannequin.

- Demonstrate the steps of measuring rectal temperature on mannequin.

- Effectively counsel mothers regarding prevention of hypothermia.

\section{Methodology}

Setting

The OSCE project was done in the department of Pediatrics Jorhat Medical College with the participation of the faculty of Department of Pediatrics and members of Medical Education Unit (MEU) of Jorhat Medical College.

\section{Subjects}

85 students of the $8^{\text {th }}$ semester MBBS batch participated in the OSCE project in August 2018.

\section{Project Approval}

The project was submitted to the Institutional Ethics Committee for approval while permission of the Dean was taken to start the project. A meeting of faculty of Department of Pediatrics was held and it was unanimously decided to introduce OSCE as assessment tool in the $8^{\text {th }}$ semester examination.

\section{Sensitization / Orientation program}

A Sensitization program of faculty/Medical Officer of Pediatrics regarding OSCE was held by the members of the MEU comprising Orientation programme regarding the project (1 hour) and Training regarding conduct of OSCE (3 hours).There was also an Orientation programme for students regarding use of the OSCE format of 1 hour duration.

As the OSCE was based on assessment of neonatal thermoregulation, a training module was prepared for the following teaching learning activities as outlined below.

Teaching Learning methods

\begin{tabular}{|l|cl|}
\hline Course content & Method & \\
\hline $\begin{array}{l}\text { Definition and grading of } \\
\text { hypothermia. } \\
\text { Management of hypothermia. }\end{array}$ & $\bullet$ & Lecture: 30 minutes \\
\hline $\begin{array}{l}\text { Demonstrate Kangaroo Mother } \\
\text { Care on mannequin for prevention } \\
\text { of hypothermia }\end{array}$ & $\bullet$ & $\begin{array}{l}\text { Demonstration on } \\
\text { mannequin:5 groups } \\
\text { (17 students each) }\end{array}$ \\
\hline $\begin{array}{l}\text { Demonstrate the steps of human } \\
\text { touch method for assessment of } \\
\text { temperature in mannequin. }\end{array}$ & $\bullet$ & $\begin{array}{l}\text { Demonstration on } \\
\text { mannequin:5 groups } \\
\text { (17 students each) }\end{array}$ \\
\hline $\begin{array}{l}\text { Demonstrate the steps of } \\
\text { measuring axillary temperature } \\
\text { using clinical thermometer on } \\
\text { mannequin. }\end{array}$ & $\bullet$ & $\begin{array}{l}\text { Demonstration } \\
\text { mannequin:5 groups } \\
\text { (17 students each) }\end{array}$ \\
\hline $\begin{array}{l}\text { Demonstrate the steps of } \\
\text { measuring rectal temperature on } \\
\text { mannequin. }\end{array}$ & $\bullet$ & $\begin{array}{l}\text { Demonstration on } \\
\text { mannequin:5 groups } \\
\text { (17 students each) }\end{array}$ \\
\hline $\begin{array}{l}\text { Counsel mothers regarding } \\
\text { prevention of hypothermia }\end{array}$ & $\bullet$ & \begin{tabular}{l} 
Role play:20minutes \\
\hline
\end{tabular} \\
\hline
\end{tabular}




\section{Conduct of the OSCE}

The OSCE was conducted in Seminar hall of the department of Pediatrics of the institute.

There were a total of eight stations comprising 2 Question stations, 4 Procedure stations, 1Observed station (on communication skills) and 1 Rest station An OSCE station map and Instruction to candidates were displayed in front of the hall.
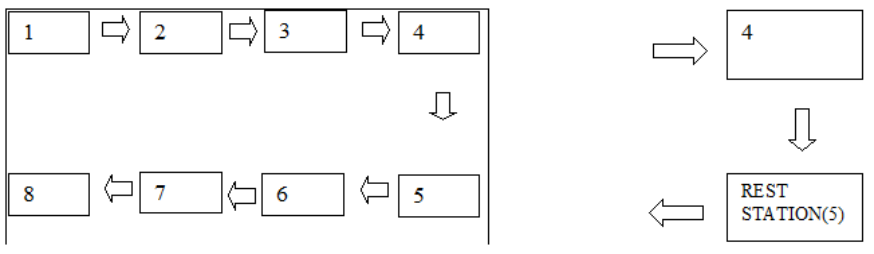

Time per station was 5 minutes.

Questions and their model keys for the response stations were prepared through consensus of all faculties. The question station involved case scenario and data interpretation related to management of hypothermia.

The procedure station included assessment of core skills like human touch method, axillary and rectal temperature measurement and Kangaroo mother care.

There was also a station on communication skill station based on case scenario.

Peer reviewed and pre validated checklist was used for marking the procedure and observed stations. Review and validation was done by faculty members of department of Pediatrics and MEU of the institute. Five faculty of the department of Pediatrics conducted the observed stations. On the day before the OSCE, the designated faculty for each station was briefed regarding the checklists, marking scheme and equipment. Four trained non medical departmental staff also helped in the process; one of whom was the time keeper.

\section{Feedback from student and faculty}

At the end of the OSCE, a structured questionnaire comprising seven attributes was used to obtain immediate feedback from the students regarding their experience of undergoing the OSCE process. They were asked to rate their experience on a 5 point Likert scale.

Feedback was also taken from the faculty of the Department of Pediatrics on a structured questionnaire comprising rating scale and open ended questions. After 1week of OSCE, the students were asked to share their perception regarding the quality of performance testing in OSCE, their suggestions on improvement and future expectations.

\section{Feedback to students}

Group feedback was given to the students by the faculty on the next day. The students were divided into 5 groups of 17 each. All the stations were revisited by the designated faculty, the answers to question stations were discussed and the steps of clinical skills demonstrated to the students. The common mistakes made during performance of clinical skills were highlighted by the faculty.

\section{Observations and Results}

Immediate feedback was given by all the 85 students who appeared for the OSCE as a part of the $8^{\text {th }}$ semester ending examination. $88.2 \%$ of students were satisfied with the OSCE experience.

- $90.6 \%$ felt that the OSCE was well structured and sequenced.

- $58.8 \%$ felt that OSCE was not stressful or intimidating while $30.6 \%$ were neutral.

- $64.7 \%$ felt that OSCE minimizes the chances of failing

- $71.8 \%$ felt that OSCE highlights areas of weakness.

- $84.7 \%$ felt that gender, ethnicity and personality do not affect OSCE scores.

- $84.7 \%$ felt OSCE should be part of formative examination.

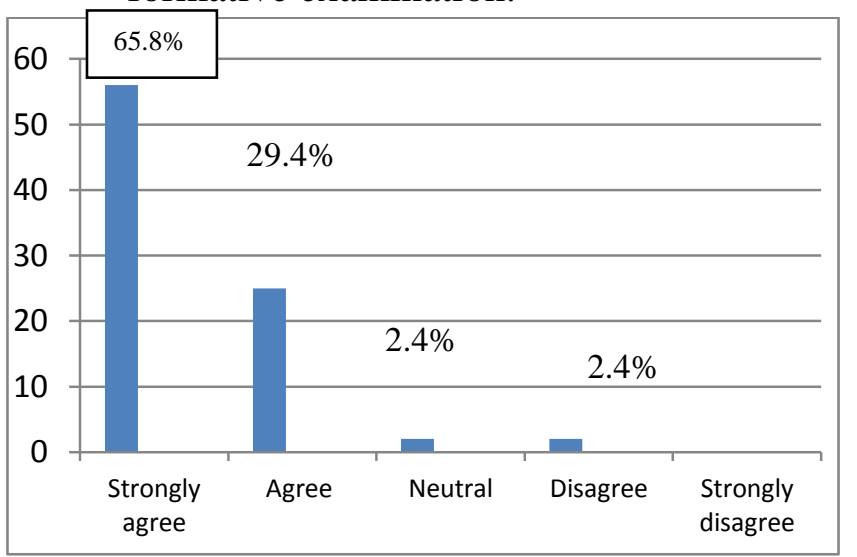

Fig no 1: Showing how well students are satisfied with OSCE. 


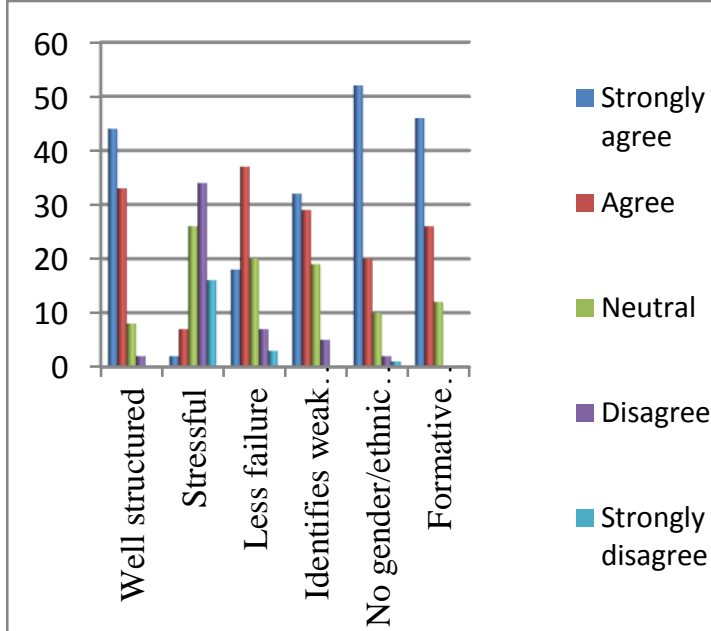

Fig no 2: Showing student's feedback about the OSCE experience.

A second feedback was taken from the students after 1week of the OSCE regarding the quality of performance testing on a six point structured questionnaire. Three open ended questions were included to get their comments and suggestions.

The following observations were made from the analysis of the students' feedback.

- $90.7 \%$ were fully aware of the nature of the exam.

- $87.7 \%$ felt that the OSCE tasks reflected those taught.

- $75.4 \%$ felt that time was adequate.

- $75.4 \%$ felt setting and context authentic

- $80 \%$ felt instructions were clear

- $90.7 \%$ felt it provided them opportunity to learn.

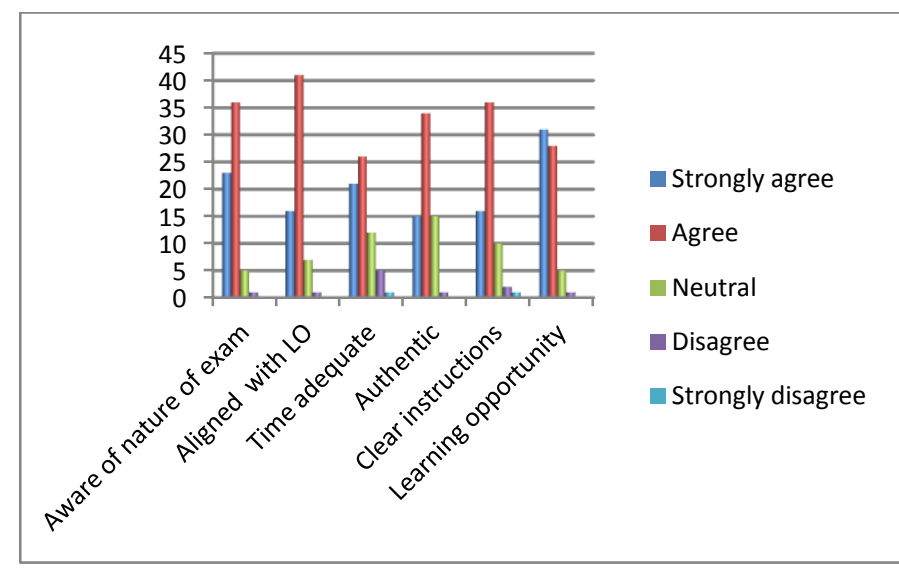

Figure no 3: Showing Student feedback on quality of performance testing in OSCE.
The comments and suggestions received though the open ended questions are summarized in Table no 1.

\begin{tabular}{|c|c|}
\hline What did you like most about the OSCE exercise? \\
- & Uniformity in assessment \\
- & Easy to score \\
- & Stations provide opportunity to learn clinical skills. \\
What did you not like about the OSCE exercise? \\
- $\quad$ Rotation of across stations troublesome and confusing \\
- $\quad$ Not acquainted with the need to perform multiple steps \\
- $\quad$ Time seemed limited for some tasks \\
\hline How is it different from other practical examinations? \\
- $\quad$ Interesting, not boring. \\
- $\quad$ More scoring \\
- $\quad$ Marking not subjective \\
- $\quad$ Assessment of communication skills \\
- $\quad$ Morior mock exercise especially during ward completion. \\
\hline
\end{tabular}

All the five faculties of the Department of Pediatrics were satisfied with the OSCE experience and want it to be included for formative assessment of undergraduate students.

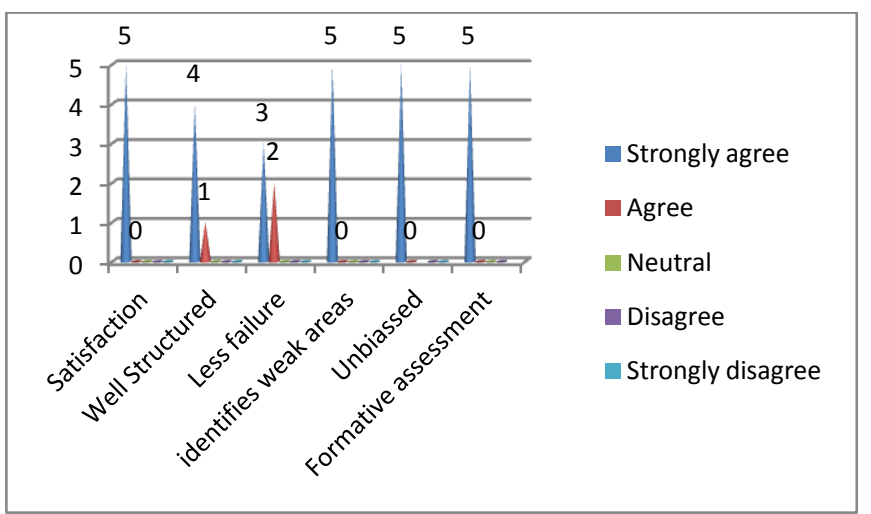

Figure no 4: Showing faculty's feedback regarding the OSCE experience.

The positive aspects of OSCE highlighted by faculty were its structured format, easy marking, and assessment of wide range of clinical skills including communication skills.

The difficult aspects were time constraints, need for trained manpower, and preparation of venue, stations, checklists and feedback forms.

They suggested that the overall quality can be further improved by faculty training and regular OSCE exercises in the future. 


\section{Discussion}

The feedback taken from students showed that majority of them $(88.2 \%)$ was satisfied with the OSCE experience and felt that it was conducted in a structured and well sequenced manner. $84.7 \%$ of the students felt that OSCE is unbiased in terms of gender and ethnicity.

Both the students and faculty were exposed to a totally new process and there was scope for much confusion and apprehension; $58.8 \%$ of students didn't feel that it was stressful. However, 30.6\% were neutral while $10.6 \%$ found it to be stressful. In a study of OSCE by Muhannad R M Salih on pharmacy students, $57 \%$ of students found OSCE to be intimidating. ${ }^{[7]}$

In the present study, $64.7 \%$ felt that OSCE minimizes chances of failing while $71.8 \%$ felt that it helped to highlight areas of weakness.

In a OSCE study in Egypt by Amina El Nemer on nursing students, majority felt that OSCE was well structured $(82 \%)$, minimized chances of failing $(91.9 \%)$, unbiased(89\%) and highlighted areas of weakness $(82 \%)^{[8] \text {. }}$

The feedback regarding the quality of performance testing was given by 65 out of 85 students. Majority of the students were aware of the nature of the exam and that it was aligned with learning objectives. However $25 \%$ felt that the time for the stations was not sufficient and the setting/context was not authentic.

$90 \%$ of students felt that OSCE gave them an opportunity to learn.

Analysis of the open ended questions showed that the students liked about the unbiased and uniform nature of assessment in OSCE. The opportunity to learn clinical skills; the focus on communication skills and faculty feedback were other important aspects of OSCE appreciated by many students. In the neonatology OSCE conducted by Piyush Gupta et al in University College of Medical Science, New Delhi, there was similar appreciation by the students regarding the assessment of clinical and communication skills in OSCE. ${ }^{[3]}$

As first timers of the OSCE method, many students felt the rotation of stations was confusing and troublesome. The need to perform clinical tasks fragmented into multiple pre-determined steps in a defined time frame was felt to be difficult by some students. In comparison to traditional clinical examinations, the students gave the opinion that even though scoring was relatively easier; one had to be more accurate in actual performance of the given tasks.

The suggestions for improvement were to conduct regular OSCE exercise in ward postings to make them acquainted with the process.

The overall verdict was that OSCE should be a part of formative examination in the future.

\section{Outcome: What this study adds}

OSCE is feasible to be introduced as a formative assessment tool in the UG curriculum.

Majority $(88.2 \%)$ of students and all faculties were satisfied with the OSCE experience and want OSCE to be part of the future assessments.

\section{Limitations}

The high reliability and validity of OSCE is due to its wider sampling. The present OSCE project is therefore constrained due to its limited topic of neonatal thermoregulation with only 8 numbers of stations.

Group feedback was given instead of individual feedback to the students after the OSCE exercise.

Lack of prior experience in organizing and conducting OSCE was another limitation.

\section{Conclusion}

OSCE is a step towards attainment of competency based education. It needs to be introduced in to the undergraduate curriculum to enrich existing assessment methods. The implementation of OSCE program needs meticulous planning, manpower, resources and faculty training. The acceptance of the OSCE project by students and faculty of Jorhat Medical College is definitely a welcome sign; however much more needs to be done in terms of further training and planning. This will ensure that the utility of OSCE remains intact leading to true 


\section{JMSCR VoI||07||Issue||08||Page 947-953||August}

enhancement of the teaching-learning-assessment processes.

\section{Implications}

The successful implementation of the OSCE project in Pediatrics is to be continued through its use in all formative departmental assessments; and subsequently in other disciplines of the institute. This will further bolster its case for inclusion in the University Curriculum at the State level.

\section{Funding: None \\ Conflict of Interest: None}

Acknowledgement: The research project was done as a part of the Advanced Course in Medical Education (ACME) of CMC Ludhiana. The author is indebted to all the faculty of MCI Nodal Centre for MET, CMC Ludhiana for their esteemed guidance and support. The author also acknowledges the support of all the faculty of the Department of Pediatrics, Jorhat Medical College.

\section{References}

1. Vision 2015: Medical Council of India, p921, 2011; www.mciindia.org, last accessed on $04 / 08 / 2018$.

2. Carraccio C, Englander R: The objective structured clinical examination: a step in the direction of competency- based evaluation; Arch Pediatric Adolescent Medicine.2000; 154(7); 736-741.

3. Piyush Gupta, Hema Jyoti Bisht: A practical approach to running an Objective Structured Clinical Examination in Neonatology for Formative assessment of undergraduate students; Indian Pediatrics, 2001; 38, 5005013.

4. Piyush Gupta, Pooja Dewan, Tejinder Singh: Objective Structured Clinical Examination (OSCE) Revisited; Indian Pediatrics; Indian Pediatrics, 2010; 47,911-920.

5. Kamran Z Khan, Kathryn Gaunt, Sankaranarayanan Ramachandran, Piyush Pushkar: The Objective Structured Clinical
Examination (OSCE): AMEE Guide No. 81.Part II: Organization \& Administration; Medical Teacher, 2013; 35: e1447-e1463

6. Madalena Folque Patricio, Miguel Juliao, Filipa Fareleira, Antonio Vaz Carneiro: Is OSCE a feasible tool to assess competencies in undergraduate medical education? Medical Teacher, Volume 35, 2013, Issue 6, 503-514.

7. Muhannad R M Salih, Mohd Baidi Bahari, Syed Azhar, Syed Sulaimam, Azmi Sarriff, Sarmed N Yaseen et al: Pharmacy Students' Perception and Feedback on the Modified Objective Structured Clinical Examination; Pharmacy Education, March 2010;10(2): 165-172.

8. Amina El-Nemer, Naheed Kandeel: Use of OSCE as an Assessment Tool for Clinical Skills: Nursing student's feedback; Australian Journal of Basic and Applied Sciences, 3(3):2009, p2465-2472. 